\title{
Os analistas de informação e a sua relação com a Ciência da Informação: histórico da integração desses profissionais
}

Marcelo Souza de Jesus ${ }^{1}$

Resumo: A informação assume uma crescente importância nas organizações como assunto de importância, pois a informação tornou-se fundamental para os sucessos empresariais, individuais e coletivos. Este artigo tem o objetivo de explanar a evolução histórica da recuperação da Informação, profissionais da informação e a Ciência da Informação e, como o Ministério do Trabalho e Emprego (MCT) estabeleceu por meio da "Classificação Brasileira de Ocupações dos Profissionais da Informação" (CBO) incluiu o profissional de tecnologia como profissional da informação, ao lado do bibliotecário, arquivista e outros.

Palavras-chave: Ciência da Informação, informação, profissional da informação.

Abstract: The information is in an increasing importance in the organizations as an important subject. Information became essential for business success, individually and collectively. This article aims to explain information retrieval historical evolution, and how "The Labor and Employment to the Brazilian Administration" established the "Information Professional Occupations" including

Key-words: Information Science; Technology Information Professional; Librarian, Arquivist and others information professional.

\footnotetext{
${ }^{1}$ Marcelo Souza de Jesus, bacharel em Administração com Habilitação em Análise de Sistemas, especialista Gestão do conhecimento e Tecnologia para gestão de Negócio, aluno especial do Programa de Pós-graduação em Ciência da Informação da Faculdade de Ciência da Informação - FCl - UNB.
} 


\section{Introdução}

A informação assume uma crescente importância nas organizações assim como para os indivíduos, pois se tornou fundamental para os sucessos empresariais, individuais e coletivos. A informação é elemento essencial na empresa moderna e, para atuar nesse ambiente informacional são necessários profissionais capacitados. 0 ambiente empresarial requer um profissional da informação que conheça as técnicas de criação, controle, disseminação e acesso à informação, com qualidade e rapidez. Nesse segmento, é importante que o profissional da informação tenha as características de empreendedor e criativo, autodidata, tenha iniciativa e flexibilidade, conheça as novas tecnologias da informação e, possa incorporar as inovações que surgem incessantemente no dia a dia da organização.

Marchiori (2002) pontua que com a evolução da informação: de maneira mais rápida ou mais lenta, planejada ou apenas disponibilizada na forma de computadores conectados à Internet, o novo século inicia-se sob uma proposta de ampla conectividade, de preocupação com os conteúdos criados, manipulados e disseminados para os públicos mais diferenciados e heterogêneos, e na revisão e determinação de competências profissionais - organizacionais e/ou individuais - que sejam responsáveis pelos processos e atividades de uma sociedade voltada para a informação e para o aprendizado.

A produção da informação vem sendo caracterizada pelo potencial tecnológico que sustentará amplo acesso à informação, sendo assim, a introdução de novas tecnologias e investimentos torna necessário a presença de um profissional da informação para organizar, e gerir a gestão da informação. Tornou-se uma estratégia para área de negócios, assim como na criação de valores e vantagens competitivas.

O surgimento de novas técnicas e tecnologias possibilitou a transferência de parte da inteligência humana para as máquinas, dotando-as de certa autonomia. Conforme Dupas (2001. p. 134), estamos vivendo numa Sociedade de Informação essa transferência de capacidades humanas para uso atemporal de informação embutida em memória de máquinas deu origem ao que se denomina, nos últimos anos, de Sociedade de Informação, isto é, ao redimensionamento dos domínios de trabalho e renda com o afastamento progressivo do homem de um espaço formal de trabalho. 
Desse modo, surge a rede inteligente de máquinas, essa rede que movimenta e altera a vida do homem e, muitas vezes, esta intervenção nem é percebida. A cada segundo está sendo gerado e processado um conjunto novo de informações (reportagens, teses, publicações, apresentações de novas tecnologias) que influenciam e definem o comportamento humano, de forma individual e coletiva. Como, por exemplo: de que forma irá se vestir, o que comer ler e até de que forma irá se relacionar socialmente.

A crescente quantidade de informações, sobretudo, informatizadas e disponíveis na Internet provoca uma profunda revisão e determinação de novas competências: profissionais, organizacionais e/ou individuais. Teremos sociedades voltadas para o aprendizado e para informação, porém teremos, simultaneamente, outras sociedades sem acesso à tecnologia da informação e aquelas sociedades que estão entre um cenário e outro (as ditas sociedades emergentes).

Frente às tecnologias, surgem alguns aspectos que merecem ser motivo de análise, segundo Marchiori (2002, p. 72 a 79) é possível observar que:

- O potencial tecnológico sustentará o amplo acesso à informação, assim como, possibilitará a convergência de diferentes tipos de informação (textual, sonoro, gráfico, visual, etc.) em entidades (ou objetos) de informação, os quais podem ser compostos e, disponibilizados de acordo com a necessidade particular de um indivíduo ou grupo.";

- A intenção de que a disponibilidade de informação e possivelmente de conhecimento possa fortalecer a democracia e a sociedade;

- A percepção de que as áreas e os setores econômicos se tornarão dependentes de uma força de trabalho que tenha acesso e possa compartilhar informação;

- O reconhecimento de que a informação, para ser acessível, deve ser organizada e gerenciada;

- $\quad$ O reconhecimento de que as habilidades de criação buscam análise e interpretações de informação são essenciais para indivíduos e grupos;

- A percepção de que as necessidades de informação se tornam cada vez mais complexas e dependentes de diferentes e múltiplas fontes - cuja correta avaliação e qualidade é fator crucial para o processo de tomada de decisão.

- O crescente desenvolvimento e substituição de tecnologias desafiam tanto as habilidades dos leigos como dos profissionais da informação, em termos de seu entendimento, domínio e gerenciamento efetivo; 
- $\quad$ O conhecimento de que o setor de informação é uma parte substancial da economia dos países.

Com esta crescente demanda de informações, as jurisdições profissionais estão se interagindo para melhorar a gestão. Estas áreas de informação com algumas características especiais a: Biblioteconomia, Arquivologia, Museologia, Tecnologia da Informação e a Administração estão no processo de busca de definição das suas atuações técnicas e práticas profissionais, no contexto brasileiro, em relação à captura, processamento e uso da informação.

Esse estudo tem como objetivo explanar a evolução histórica da recuperação da Informação, profissionais da informação e da Ciência da Informação. Especificamente, foi feito um estudo sobre a evolução histórica de como o profissional da informática se integrou a esta jurisdição.

Segundo Braga (1999), a Ciência da Informação como em qualquer disciplina emergente, as primeiras pesquisas tomaram emprestado métodos de outras 118 disciplinas, adaptaram outros métodos e técnicas e, gradualmente, foram construídos conjuntos de conceitos e teorias, na tentativa de alicerçar os fundamentos da nova área.

Neste contexto, a literatura tem mostrado por meio de estudos e discussões em relação aos perfis, práticas e desafios como os profissionais se agregam em relação à informação. Para entender quais profissionais fazem parte desta ciência, o Ministério do Trabalho e Emprego (MTE) disponibiliza à sociedade a Classificação Brasileira de Ocupações (CBO) Esse documento reconhece, nomeia, codifica os títulos e, descreve as características das ocupações do mercado de trabalho brasileiro.

\section{Evolução histórica da Ciência da Informação}

A Ciência da Informação nasceu de estudos que discutiam os modelos da documentação e da recuperação da informação. Na época, havia a preocupação de cientistas em reunir, organizar e tornar acessível o conhecimento cultural, científico e tecnológico produzido em todo mundo. O paradigma da Ciência da Informação 
compõe-se de um grupo de idéias relativas ao processo que envolve o movimento da informação em um sistema de comunicação humana.

O fenômeno da "explosão da informação", (relacionado com o renascimento científico depois da 2a Guerra Mundial) gerou esforços para "controle bibliográfico" e para o tratamento da documentação, implícita no processo. Teria surgido, conseqüentemente, de uma necessidade específica no âmbito da indústria da informação, na tentativa de organizar a literatura científica e técnica, por meio de serviços e produtos para as comunidades especializadas. Essa tarefa migrou das bibliotecas tradicionais para os outros sistemas informacionais, com a participação de profissionais de diferentes áreas do conhecimento, conhecidos como "Centro de Documentação e Informação".

Neste aspecto, a informação ganhou valor para tomadas de decisões. Desta forma, a informação torna-se uma estratégia, mas que precisa ser organizada. De acordo com a descrição de Robredo (2003):

"a informação é um conhecimento inscrito (gravado) sob forma escrita (impressa), oral ou audiovisual (...)" como a sugerir que os documentos inscrevem informações, mas eles são ao mesmo tempo, objetos autônomos, sendo assim o conteúdo informacional dos documentos seria objeto de análise de cada ciência a ele relacionada.

Neste processo de entendimento de informação pós-guerra, fez se necessário entender a necessidade de suporte para estes grandes acervos. Um deles foi o profissional de informática que se integrou no processo com a entrada dos computadores. Nesta mesma época, os computadores tinham valores de compra tão grande, que apenas as grandes instituições poderiam ter uma máquina e, que não era disponibilizada a muitos.

Para o entendimento da introdução da Informática na jurisdição da Ciência da Informação, tem-se que voltar a 1938 a 1942 quando o presidente Roosevelt designou Vannevar Bush responsável pelo Comitê Nacional de Pesquisa, que tinha como missão congregar cientistas americanos e europeus para direcionar a esforços de guerra. Em 1939, Bush escreveu um artigo para o periódico Atlantic Monthly. Posteriormente, publicado a Revista Life. Neste artigo, o autor fazia varias observações e alertas sobre o futuro das aplicações da informação. No ano de 1945, ele escreveu As We way think 
(Como nós pensamos), sobre o problema da informação em ciência e tecnologia, além relatar as possíveis dificuldades para organização e repasse. Dessa forma, pode-se considera Bush como oo pioneiro da Ciência da Informação. Na época da publicação do seu artigo, ele citou a mudança de paradigma envolvendo Ciência da Informação e a Tecnologia e seus profissionais. Ele ainda introduziu associações ao processo de armazenamento e recuperação da informação. O processo seria basicamente operacionalizado como nos pensamentos, em que se transforma a informação em conhecimento (BARRETO, 2008).

A construção de uma máquina chamada $\operatorname{Memex}^{2}$ (resultado da expressão memory expander), serviu como um utensílio tecnológico para armazenar e recuperar documentos por meio de associações de palavras. A idéia causou tremenda euforia, na época, entre a comunidade científica. Em 1946, um ano após o término da Segunda Guerra foi realizada em Londres, a conferencia Royal Empire Society Scientific Conference. Nessa conferencia, se discutiu a importância da informação. Em 1948, a mesma conferência foi realizada e, cerca de 340 cientistas e documentalistas de todo mundo compareceram para uma discussão de 10 dias úteis. Os anais da conferencia de 723 páginas divididas em dois volumes levaram dez anos para ser publicado e, foi editado nos Estados Unidos. Após esta publicação, cientistas começaram a trabalhar com o assunto. Para não perder seu status acadêmico, a nova área foi criada com o nome "Ciência da Informação", e dessa maneira, Vannevar Bush foi considerado um precursor da área por suas idéias (BARRETO 2008 p. 22).

Em 1952, os profissionais da Ciência da Informação fundaram o "Instituite for Information Scientists" sob o comando de Ferradame com o primeiro curso de pósgraduação em Ciência da informação na "The City University". Visando o futuro, os estudos desta área foram iniciados em uma faculdade de alta tecnologia para a época,

\footnotetext{
${ }^{2}$ O Memex é uma máquina um tanto quanto visionária para auxiliar a memória e guardar conhecimentos (daí o nome Memex: Memory Extension) que foi pensada pelo cientista americano Vannevar Bush e anunciada em $\underline{1945}$, em um célebre artigo intitulado As We May Think. A partir da idéia de que a soma dos conhecimentos, aumentando em um ritmo prodigioso, não encontrava contrapartida em relação à evolução dos meios de armazenamento e acesso aos dados e observando o funcionamento da mente humana, segundo ele, operando sempre por meio de associações, Bush imaginou e descreveu, de maneira detalhada, uma máquina capaz de estocar montanhas de informações, fácil e rapidamente alcançáveis. Tal engenho, concebido para suprir as "falhas da memória humana", através de recursos mecânicos, é considerado o precursor da idéia de hipertexto. (Nielsen,1995).
} 
vinculada, inicialmente, ao Centro de Administração e Negócios da referida universidade (BARRETO 2008 p. 22).

Outro estudo detectou natureza da Ciência da Informação, sob a denominação de Informática, os precursores foram os russos Mikhailov, Chernyi e Gilyarevskyi (1975, traduzido ao português em 1980). Ao estudar "a estrutura e as principais propriedades da informação científica" eles apontaram prioritariamente para a "inseparabilidade da informação científica de seu suporte físico", reconhecendo, em seguida, que essa propriedade é comum a todo tipo de informação (AQUINO 2002).

Em 1980, o custo da memória digital caiu de preço, permitindo o processamento de textos e linguagem natural. Assim apareceu o computador e a Ciência da Informação se alinhou ainda mais com a tecnologia, pois os profissionais da área puderam ter acesso à máquina.

A criação da tecnologia de impressão foi muito importante no desenvolvimento das forças produtivas na sociedade, ao facilitar a circulação da mesma informação, com um alcance sem precedentes. Inicia-se, então, um processo de comunicação

121 científica, na medida em que a produção de conhecimentos gera, por sua vez, a necessidade de novos conhecimentos. Isso merece ser destacado, uma vez que nesse período foram iniciadas as bases da Ciência da informação atual, que começou a ser construída quando as associações científicas foram criadas e os primeiros periódicos científicos são publicados, dando início à formalização do processo de comunicação científica (SARACEVIC, 1996).

A partir desse período, a atividade científica, baseada no método de experimentação e na matemática, estabelece um novo paradigma social e tecnológico. Nesse contexto, desenvolve sua própria forma de expressão e canais de comunicação. Nesta fase são criadas as primeiras associações científicas. Dessa maneira, percebe-se no processo histórico, que os profissionais de informação vão estar sempre próximos dos cientistas, seja na organização e na armazenagem das informações produzidas ou na sua comunicação.

Saracevic (1966) descreve que Ciência da informação é um campo dirigido à investigação cientifica e a prática profissional, relacionada aos problemas de efetiva comunicação do conhecimento e, registro do conhecimento entre humanos, nos 
contextos de uso social, institucional e/ou individuais e de necessidades de informação. As características apontadas foram:

- é interdisciplinar;

- inexoravelmente conectada com a tecnologia da informação, e

- ativa e deliberadamente participante na evolução da sociedade humana.

No otimismo global de produtos e serviços, a informação tem cada dia mais excelência segundo Marchiori (2002) a sociedade da informação cria mais força e estrutura para sua efetivação. Dessa maneira, com o avanço tecnológico e o grande fluxo de informação no meio digital, se fez necessário cada vem mais a presença do profissional da área tecnológica para dar suporte a esta explosão, seja na disseminação ou na recuperação da mesma.

\section{Recuperação da Informação}

A partir do uso de computadores surgem os bancos de dados e as mídias como suporte digital. Para tanto, foram criados uma variedade de conceitos e construtos teóricos, empíricos e pragmáticos, bem como numerosas realizações práticas.

Muitos exemplos históricos podem ilustrar a marcante evolução de sistemas, técnicas e/ou máquinas utilizados para recuperação da informação. Saracevic (1996) afirma que:

[...] a variedade dos cartões perfurados aos CD-ROMs e acesso online; dos sistemas não-interativos àqueles de múltiplas possibilidades de interação, com interfaces inteligentes, transformando a recuperação de informação em um processo altamente interativo; de bases documentais para bases de conhecimento; dos textos escritos aos multimídia; da recuperação de citações à recuperação de textos completos; e ainda aos sistemas inteligentes e de respostas a perguntas.

Até hoje, ainda existe uma grande dificuldade das organizações em sistematizar e usar informações para promover melhorias constantes em processos de gestão de projetos em suas diversas atividades. Muitas ferramentas, destacadamente as baseadas em tecnologia da informação (TI), foram concebidas e apresentadas ao mercado como soluções capazes de viabilizar o acesso e uso da informação. Para 
Albertin (1999), "tecnologia da informação" é tudo aquilo com que se pode obter, armazenar, tratar, comunicar e disponibilizar a informação. De acordo com Rezende (2000) a TI está fundamentada nos seguintes componentes: hardware e seus dispositivos periféricos; software e seus recursos; sistemas de telecomunicações, gestão de dados e informações. Sendo que "informação e conhecimento são, essencialmente, criações humanas e, nunca seremos capazes de administrá-las se não levarmos em consideração que as pessoas desempenham, nesse cenário, um papel fundamental" (DAVENPORT, 2000, p. 11).

A quantidade de informação tratada e organizada deu origem a debates a acerca das melhores e mais adequadas soluções (técnicas, conceitos, sistemas etc). Saracevic (1996 p. 44) descreve que Calvin Mooers criou o termo "Recuperação da Informação" em 1950, destacando que engloba os aspectos intelectuais da descrição de informações e suas especificidades para a busca, além de quaisquer sistemas, técnicas ou máquinas empregadas para o desempenho da operação.

Entretanto, apesar de Mooers em 1950 ter criado o termo "recuperação da 123 informação", o belga, Paul Otlet ${ }^{3}$, foi reconhecido como o "pai" da documentação, já no século XIX, ao idealizar e sistematizar as questões teóricas presentes para o problemático crescimento exponencial dos documentos, e por estabelecer metodologias e técnicas na tentativa de solucionar a questão da recuperação, acesso e circulação da informação. (SANTOS p. 147 2006).

Quanto à recuperação da informação, o objetivo de Mooers era de tornar acessível o conhecimento disponível àqueles que dele necessitam. $\mathrm{O}$ autor utiliza o conceito expandido de documentação e da tecnologia, disponível para abordar os principais problemas bibliográficos, por entender que os registros bibliográficos não se resumem aos livros. (PEREIRA, 2000, p. 8).

A explosão da informação gerou a necessidade de organização para recuperação da mesma tornaram-se bem sucedida por conta da introdução homem e

3 Paul Otlet visionou a idéia de um novo meio para a pesquisa, recuperação da informação e também a leitura e escrita de textos através de uma base de dados mecânica armazenada em minhões de fichas $3 \times 5$. Este instrumento não só permitiria a pesquisa como a conexão entre os documentos, as pessoas poderiam acessar as informações através de um "telescópio elétrico". Ele foi o inventor da palavra "link", que descreve as relações entre termos/documentos. 
máquina conforme a definição de Mooers (1951). Essa simbiose de homem e sistema de informação por meio de periféricos, denominados interfaces, amplia as capacidades humanas a ponto de determinadas tarefas poderem ser, integralmente, entregues aos sistemas informáticos. Assistimos, pois, a uma diluição da fronteira homem-máquina. "Em outras palavras, o lado tecnológico da equação homem-tecnologia está em contínua expansão" (SARACEVIC, 1996, p.56).

Segundo os autores Davenport e Prusak (1998) as ferramentas de "tecnologia de Informação" podem ser úteis, porém é importante ressaltar que por mais que os sistemas estejam cada vez mais completos, sua existência e aplicação, coexistem com o fator humano.

\section{A importância do usuário da informação}

O trabalho determinado pela necessidade de recuperar informações gerou questões e, promoveu pesquisas exploratórias de fenômenos, processos e variáveis, bem como das causas, efeitos, comportamentos e manifestações relacionados. Historicamente, este fato resultou em estudos teóricos e experimentais sobre: a natureza da informação, a estrutura do conhecimento, seus registros, o uso e os usuários. Esses estudos resultaram na compreensão do comportamento humano frente à informação; interação homem-computador, com ênfase no lado humano da equação; relevância, utilidade; obsolescência e, outros atributos do uso da informação, juntamente com medidas e métodos de avaliação dos sistemas de recuperação da Informação; economia, impacto e valor da informação, dentre outros. (SARACEVIC, 1996).

O desenvolvimento dos sistemas de recuperação da informação gerou a necessidade de um profissional da área de tecnologia, por exemplo, o "analista de sisstemas". Segundo Borges (2004 p. 56) isso requereu a presença de um profissional especializado na área de computação, pois o avanço tecnológico alterou a noção de espaço e tempo. Este profissional ficou responsável pelo relacionamento homem, máquina e sistema. Neste mesmo contexto, o trabalho deste mesmo profissional é responsável pelo desenvolvimento de inúmeras aplicações (produtos, sistemas, redes, 
serviços), tudo isso para promover a disseminação da informação/conhecimento. Saracevic (1996 p. 50) em seu artigo definiu que o profissional da tecnologia contribuiu ao desenvolvimento da Ciência da Informação por meio da evolução na recuperação da informação.

\section{Profissionais da Informação e a Ciência da Informação}

A valorização da informação define a competitividade entre as pessoas, grupos, produtos e serviços. Neste cenário Borges (2004 p. 56), delineia os impactos nos vários setores da vida econômica e social, das instituições, das empresas e dos indivíduos, com profundas alterações na estrutura vigente entre fronteiras geopolíticas. Sendo assim o profissional de informação tradicional (bibliotecário) precisa se atualizar, constantemente, para se manter atuante neste novo panorama. Esse novo profissional da informação está integrado à área com forte conhecimento em gestão do conhecimento e habilidades para agregar valor ao profissional da informação tradicional. (MACHIORI, 2002).

O surgimento dos sistemas automatizados de recuperação da informação é considerado o sustentáculo para surgimento da Ciência da Informação. A situação, após a Segunda Guerra, despertou, notadamente, nos países desenvolvidos, um grande interesse pelas atividades de ciência e tecnologia, ocasionando um aumento considerável de conhecimentos (Barreto, 2007). Esse fenômeno, Saracevc (1996) denomina como "explosão de informação", caracterizou-se por um crescimento exponencial de registros de conhecimento, particularmente em ciência e tecnologia. Tal fenômeno trazia em sua essência um problema básico, que era a tarefa de tornar mais acessível um acervo crescente, proveniente daqueles registros.

A introdução do computador no tratamento e na recuperação da Informação de maneira sistemática trouxe novas perspectivas para serviços de informação (Aquino 2002). O computador permite um comportamento mais breve e racional no tratamento da informação, além de possibilitar a manipulação de grande quantidade de dados (Saracevic, 1999). Já Andrade (2005) afirma que o trabalho com a 
recuperação de informações deu subsídio para o desenvolvimento de inúmeras aplicações, por exemplo: programas, sistemas, redes e serviços.

Ao mesmo tempo em que estas tecnologias foram introduzidas na Ciência da Informação, o profissional da tecnologia e da informação foi inserido com competências definidas. Segundo Neves (1998), a expressão "Profissional da Informação" surge na literatura, a partir do final da década de 80 e início da década de 90, para atender a uma necessidade das unidades de informação, que trabalham, principalmente, com a realidade das novas tecnologias.

Esta "ciência do tratamento da informação [...]. Inclui desde recursos lógicos (software), como linguagens, algoritmos, cálculos e gerência, até recursos físicos ou material (hardware, como processadores, periféricos, terminais, memória, blocos e componentes" (FRAGOMENI apud RONDINELLI, 2002, p. 24).

Os profissionais de informática devem dar suporte aos profissionais da informação quanto ao processamento e gerenciamento da informação, estando a informação em meio eletrônico ou em suportes tradicionais. As principais atividades desse profissional são: criação e manutenção de base de dados de controle e produção de documentos; desenvolvimento de sites e portais virtuais; além da manutenção e atualização dos softwares e hardwares disponíveis.

\subsection{O profissional da informação e a Classificação Brasileira de Ocupações (CBO)}

Em 2002, o Ministério do Trabalho e Emprego (MTE) disponibilizou a sociedade a nova Classificação Brasileira de Ocupações (CBO), que veio substituir à anterior, de 1994. Esse documento reconhece, nomeia, codifica os títulos e, descreve as características das ocupações do mercado de trabalho brasileiro. Segundo a CBO a existência de uma dimensão estratégica é importante, na medida em que, com a padronização de códigos e descrições, poderão ser utilizados pelos mais diversos atores sociais do mercado de trabalho. A normalização dessa área serve, também, para a integração das políticas públicas do MTE, sobretudo no que dizer respeito aos programas de qualificação profissional e intermediação da mão-de-obra, bem como no controle de sua implementação. 
De acordo com atual CBO, por meio da palavra-chave Informática, relaciona os seguintes profissionais da tecnologia:

\begin{tabular}{|c|c|c|}
\hline Resultados de Títulos Encontrados & Código & Tipo \\
\hline Analista de sistemas (informática) & 2124-05 & Sinônimo \\
\hline Diretor de informática & $1236-05$ & Sinônimo \\
\hline Diretor de serviços de informática & $1236-05$ & Ocupação \\
\hline Diretores de serviços de informática & 1236 & Família \\
\hline Instrutor de aprendizagem em informática & $2332-25$ & Sinônimo \\
\hline Instrutor de informática & $2332-25$ & Sinônimo \\
\hline Operador de sistemas de informática (teleprocessamento) & $3722-05$ & Sinônimo \\
\hline Pesquisador em ciências da computação e informática & 2031-05 & Ocupação \\
\hline Professor de informática (no ensino superior) & $2341-20$ & Sinônimo \\
\hline $\begin{array}{l}\text { Professores de matemática, estatística e informática do } \\
\text { ensino superior }\end{array}$ & 2341 & Família \\
\hline Técnico de apoio ao usuário de informática (helpdesk) & $3172-10$ & Ocupação \\
\hline Técnico em manutenção de equipamentos de informática & $3132-20$ & Ocupação \\
\hline Técnico de apoio ao usuário de informática (helpdesk) & $3172-10$ & Ocupação \\
\hline Técnico em manutenção de equipamentos de informática & $3132-20$ & Ocupação \\
\hline
\end{tabular}

Fonte: http://www.mtecbo.gov.br/cbosite/pages/home.jsf - janeiro de 2011

A lista acima ilustra os resultados obtidos sobre profissionais da tecnologia de informação, no qual direciona a família codificada sob o número 2124, ou seja, "Analistas de tecnologia da informação". Ao pesquisar o perfil sob código 2124 na CBO, obtêm o seguinte resultado:

\section{4 : Analistas de tecnologia da informação}

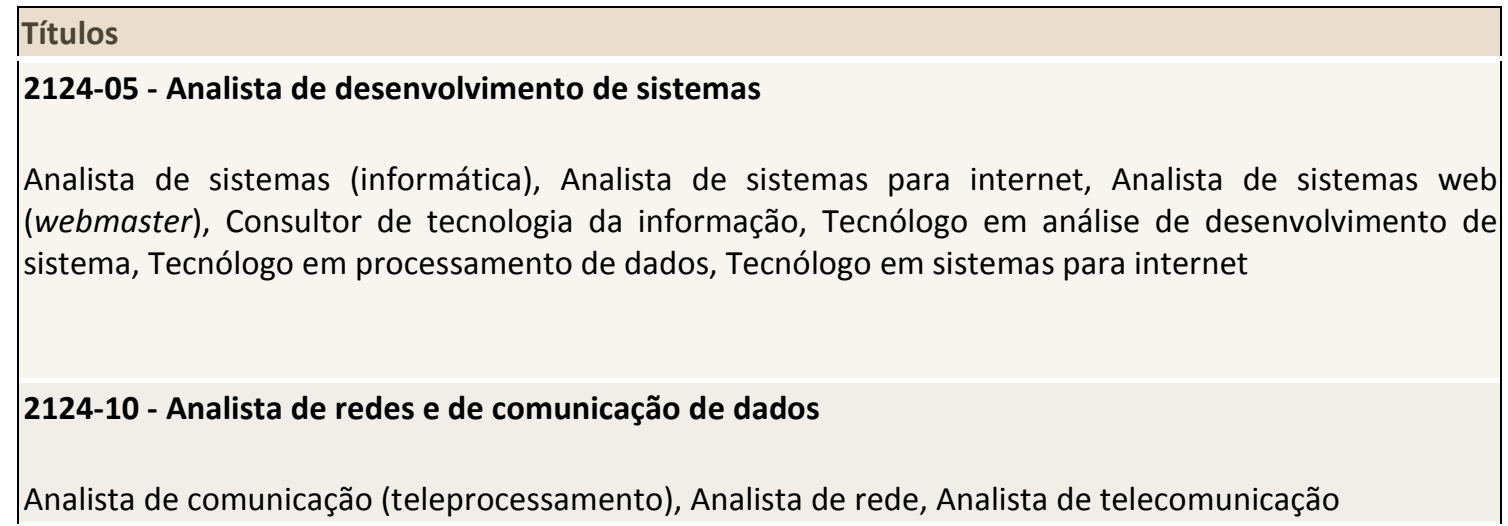




\begin{tabular}{|l|}
\hline Títulos \\
2124-15 - Analista de sistemas de automação \\
2124-20 - Analista de suporte computacional \\
Analista de suporte de banco de dados, Analista de suporte de sistema, Analista de suporte técnico \\
\begin{tabular}{|l} 
Descrição Sumária \\
sistemas, especificando sua arquitetura, escolhendo ferramentas de desenvolvimento, especificando \\
programas, codificando aplicativos. Administram ambiente informatizado, prestam suporte técnico ao \\
cliente, elaboram documentação técnica. Estabelecem padrões, coordenam projetos, oferecem \\
soluções para ambientes informatizados e pesquisam tecnologias em informática.
\end{tabular} \\
\hline
\end{tabular}

Fonte: http://www.mtecbo.gov.br/cbosite/pages/home.jsf - janeiro de 2011

No resultado obtido, percebem-se as competências, tais como: conhecimento e habilidades atribuídas ao profissional da tecnologia. Percebe-se que cada um tem uma designação adequada para sua formação profissional.

Alguns autores como (CUNHA 1985, DAVENPORT 2000, MARCHIORI 2002 e ROBREDO 2003), relatam que este novo cenário globalizado nos remete a quebra de paradigmas quanto à jurisdição e competências dos profissionais, pois a inserção e viabilidade de tecnologia modificam as relações de trabalho, na busca de agilidade e estratégias, além de inovação e ferramentas nas mais diversas competências jurisdicionais.

O que caracteriza a atual revolução tecnológica não é a centralidade de conhecimentos e informação, mas a aplicação desses conhecimentos e de dispositivos de processamento/comunicação da informação, em um ciclo de realimentação cumulativo entre a inovação e seu uso. (CASTELLS, 1999, p. 69).

A interdisciplinaridade e a multidisciplinaridade e, sobretudo o rigor científico da pesquisa em ciência da informação (...) apontam também para a multidisciplinaridade da participação de profissionais de origens e formações diversificadas (ROBREDO, 2003, p. 162-163).

Verifica-se que a sociedade contemporânea vem apresentando modificações sensíveis na aquisição, no processamento e no acesso a informações, com base na proliferação, qualidade e publicação dos recursos tecnológicos. Essa é uma realidade nos países desenvolvidos, 
cuja preocupação, hoje, é a definição de padrões de troca de informações, a utilização dos recursos computacionais e de telemática, bem como a modificação dos mercados de trabalho no que diz respeito aos perfis dos profissionais que neles atuam (MARCHIORI, 1997).

Segundo Saracevic (1999) a revolução informação foi essencial para os interesses do capital, pois ela se apoderou da concentração das riquezas e do poder e ainda atende as necessidades do capitalismo. Algumas características da sociedade da informação e do conhecimento interferem diretamente na atuação do profissional da informação. (Borges, 2004). Isso é de fato, vivenciado no dia a dia, onde somos obrigados a fazer parte da sociedade que quase tudo funciona através de tecnologia avançada e muito capital.

Quanto ao impacto causado pela revolução tecnológica sobre as políticas econômicas mundiais, Castells (1999 p.53) acrescenta que: um grande aumento repentino e inesperado de aplicações tecnológicas transformou os processos de produção e distribuição, criou uma enxurrada de novos produtos e mudou de maneira decisiva a localização das riquezas e do poder no mundo.

Os novos meios tecnológicos segundo Saracevic (1999) modificam as noções de tempo e espaço, acrescentam velocidade das trocas de idéias e mensagens, possibilitam a quebra de fronteiras, fazendo com que as organizações passem por grandes modificações, pois seus membros e estrutura não necessitam mais estar sobre o mesmo teto para desenvolver seus trabalhos.

Mas, para que toda essa tecnologia possa funcionar, o analista de sistemas produz e cria suportes para manter o funcionamento adequado destes sistemas.

Os profissionais da área da computação geram softwares, que são executados em hardwares operados por usuários preparados e treinados em procedimentos operacionais padronizados, dotados de conhecimentos do software e hardware para seu trabalho. A partir disso, a "análise de sistemas" é uma profissão, cuja responsabilidade concentra-se na análise do sistema e na administração de sistemas computacionais. Cabe a este profissional parte da organização, implantação, manutenção de aplicativos e redes de computadores, ou seja, o analista de sistemas é 
o responsável pelo levantamento de informações sobre uma empresa a fim de utilizálas no desenvolvimento de um sistema, para a mesma ou para o levantamento de uma necessidade do cliente com o objetivo de desenvolver um programa específico,com base nas informações colhidas.

Segundo Arruda et al (2000, p.17) esse profissional, geralmente, possui conhecimento adquirido em faculdades de Sistemas de informação, Ciência da computação, Análise de sistemas, Processamento de dados e Programação, Informática e, ou outras disciplinas similares.

O trabalho desse profissional está no processo de desenvolvimento de

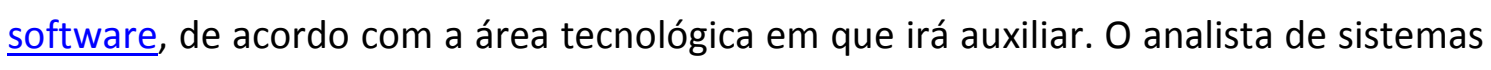
deve servir como um tradutor entre as necessidades do usuário e o programa a ser desenvolvido pelo programador. Para isto, deve ter conhecimento abrangente da área de negócio para o qual o sistema deve ser desenvolvido, para que possa implementar, corretamente, as regras de negócio.

A partir do entendimento sobre a inclusão do profissional da tecnologia na 130 Ciência da Informação, é possível compreender que esta junção tem como finalidade o processamento da informação, a fim de adequar/direcionar o melhor caminho para que possa ser viabilizada e apropriada. Esse mesmo profissional cria aplicações para desenvolvimento de soluções na recuperação da informação.

Neste contexto segundo Saracevic (1996), a base da relação entre Ciência da Informação e Ciência da computação reside na aplicação dos computadores e da computação na recuperação da informação, assim como nos produtos, serviços e redes associadas. Para esclarecer a conexão, tem-se a definição de Denning (1989) que afirma ser a disciplina da computação um estudo sistemático dos processos algorítmicos que descrevem e transferem informações; sua teoria, análise, desenho, eficiência, implementação e aplicação.

Segundo Castells (1998), as tecnologias informacionais podem aumentar a autonomia dos indivíduos e multiplicar suas capacidades cognitivas, como por exemplo, a extensão da memória em longo prazo e a leitura individualizada de hipertextos. Saracevic (1996) ressalta que uma das áreas chave de interesse para ambas, ciência da computação e $\mathrm{Cl}$, é a informação. A Ciência da Informação vem se modernizando, 
alargando e contextualizando novos profissionais foram agregando à área. Novas propostas epistemológicas e metodológicas foram adicionadas de forma a compor o quadro.

\section{Considerações finais}

Como visto nesse estudo, a Ciência da Informação $(\mathrm{Cl})$ desde o seu nascimento até sua ascensão de uma natureza interdisciplinar, como afirma, Robredo (2003) a interdisciplinariedade e a multidisciplinariedade faz com que estes dois campos distintos tragam para a $\mathrm{Cl}$ a participação de profissionais dediversas origens, visões e formações diversas.

Nesta reflexão, com autores que se dedicaram a discussão das delimitações da $\mathrm{Cl}$ e seus profissionais, Castells, Marchiori, Robredo e Saracevic entre outros, percebeu-se que o desenvolvimento científico e tecnológico tem um potencial considerável em aplicações práticas de processamento de recuperação da informação, modelos de realimentação e de relevância para recuperação, redes de citação, análise

131 lingüística para indexação automática, hardware dedicado à automação, entre outras aplicações. Para que tudo isso possa funcionar, o profissional da tecnologia da informação agregou agilidade com o uso de computadores e desenvolvimento de sistemas.

O profissional da TI incrementa a Ciência da Informação, com ênfase na tecnologia do processamento da informação (origem, coleta, organização, armazenamento, recuperação, interpretação, transmissão, transformação e utilização da informação). Nesta conjuntura, o compartilhamento de novas idéias e experiências destes profissionais para superação de barreiras funcionais das jurisdições. Por outro lado, a TI aplicada procura disseminar e atingir a necessidade da informação por meio de suporte e outros meios, em que a $\mathrm{Cl}$ e a $\mathrm{TI}$, em conjunto, obtêm mais agilidade em seus processos para gerenciamento, segurança, qualidade da informação para o usuário da informação. 


\section{Referências}

ALBERTIN, A. L. Administração de informática: funções e fatores críticos de sucesso. São Paulo: Atlas, 1999.

ARRUDA, M.C.C; MARTELETO, R.M.; SOUZA,D.B. Educação, trabalho e o delineamento de novos perfis profissionais: o bibliotecário em questão. Ciência da Informação, Brasília, v. 29, n.3, p. 14-24, set. / dez. 2000.

AQUINO, Mirian de Albuquerque. O Campo da Ciência da Informação: gênese, conexões e especificidade. João Pessoa: Editora Universitária/ UFPB, 2002 p. 9-24.

BARRETO, Aldo de A. Para entender Ciência da Informação. Salvador, Bahia, EDUFBA, 2008.

BORGES, Maria Alice G. O profissional da informação: somatório de formações, competências e habilidades. IN: Baptista, Sofia G.B. et al. Profissionais da Informação: o espaço de trabalho, 2004 p.55-69 Disponível em:

http://repositorio.bce.unb.br/bitstream/10482/1447/1/

BRAGA, Gilda Maria. Informação, ciência da informação: breves reflexões em três tempos. Ciência da Informação, 24(1), 1995.

BRASIL. Ministério do Trabalho. Classificação brasileira de ocupações. Brasília, 2002.

Disponível em: <http://www.mtecbo.gov.br/index.htm>. Acesso em: Janeiro 2011.

CASTELLS, Manuel; $A$ sociedade em rede: a era da informação: economia, sociedade $e$ cultura; São Paulo: Paz e Terra, 1999.

CUNHA, Murilo Bastos. Reflexões sobre a informática na Biblioteconomia. Boletim ABDF. Nova Série, Brasília, v.8, n.3, p.180-186, jul./set. 1985.

132 DAVENPORT, T.; PRUSAK, L. Conhecimento empresarial. Rio de Janeiro: Campus, 1998. DAVENPORT, T. H. Ecologia da informação: por que só a tecnologia não basta para o sucesso na era da informação. São Paulo: Futura, 2000.

DENNING, P.J. et al. Computer as a discipline. Communications of the ACM, v. 32, n.1, p. 9-23, 1989.

DUPAS, Gilberto. Ética e poder na sociedade da informação: de como a autonomia das novas tecnologias obriga a rever o mito do progresso. 2. ed. ver. ampl. São Paulo: Ed. UNESP, 2001. p. 134.

LE COADIC, Yves-François. A ciência da informação. Brasília: Briquet de Lemos/Livros, 1996. p. 122.

MARCHIORI, P.Z. "Ciberteca" ou biblioteca virtual: uma perspectiva de gerenciamento de recursos de informação. Ci. Inf, .v. 26, n. 2, p. 114-24, maio/ago. 1997.

A ciência e a gestão da informação: compatibilidade no espaço profissional. Cl. Inf., Brasília, v.31, n .2, p.72-79 maio/ago, 2002.

MIKHAILOV, A .I.; CHERNYI, A .I.; GILJAREVSKYI, R. S. Estrutura e principais propriedades da informação científica (a propósito do escopo da informática). In: Gomes, Hagar Espanha, org. Ciência da Informação ou Informática?, Rio de Janeiro: Calunga, 1980, p. 71-89.

MOOERS, C.N. Zatocoding applied to mechanical organization of knowledge. American Documentation, v. 2, p. 20-32, 1951.

NEVES, Elisabete da Cruz. Perfil do moderno profissional da informação. Marília, 1998. 53 f. (Síntese da monografia. Departamento de Biblioteconomia e Documentação - 
Faculdade de Filosofia e Ciências da Universidade Estadual de São Paulo, Campus de Marília)

NIELSEN, J. Multimedia and Hypertext: the Internet and Beyond. Academic Press Professional, 1995 p.33.

PEREIRA, Maria de Nazaré Freitas. Prefácio que esclarece o leitor a propósito do sonho de Otlet: aventura em tecnologia da informação e comunicação. In: PEREIRA, Maria de Nazaré Freitas, PINHEIRO, Lena Vânia Ribeiro. O sonho de Otlet: aventura em tecnologia da informação e comunicação. Rio de Janeiro: IBICT, 2000, p. 291.

ROBREDO, Jaime. Da Ciência da informação revisitada: aos sistemas humanos de informação. Brasília, 2003.

RONDINELLI, Rosely Curi. Gerenciamento arquivístico de documentos eletrônicos. Rio de Janeiro: FGV, 2002.

SANTOS, P. de M. L. dos. O ponto de inflexão Otlet: uma visão sobre as origens da documentação e o processo de construção do princípio monográfico. 2006, $146 f$. Dissertação (Mestrado em Ciência da Informação) - Escola de Comunicação e Artes, Universidade de São Paulo, São Paulo, 2006. Disponível em: <http://poseca.incubadora.fapesp.br/portal/bdtd/2006/2006-mesantos_paola.pdf>. Acesso em: 16 de fev. 2011.

SARACEVIC Tefko, Jornal da Sociedade Americana da Ciência da Informação. Universidade Rutgers, EUA, Out. 1999

p. 41-62, jan./jun. 1996. 